\title{
Programa de Manejo del Ordeño: Procedimientos de Ordeño Adecuados para Optimizar la Eficiencia del Ordeño y la Calidad de la Leche ${ }^{1}$
}

Izabella Toledo ${ }^{2}$

Esta publicación esta destinada al personal de trabajo encargado de las labores diarias de la producción en establecimientos de producción de leche.

Las prácticas de ordeño consistentes y eficientes pueden mejorar el rendimiento del hato y la calidad de la leche. El objetivo principal de un programa de manejo de ordeño adecuado es cosechar leche de alta calidad mediante el ordeño de los pezones limpios y secos, de manera suave, rápida y completa, mientras se minimizan las infecciones de mastitis y se reduce el estrés tanto en las vacas como en los trabajadores de la sala de ordeño.

El primer paso para tener un programa de manejo de ordeño exitoso es establecer y comprender adecuadamente una rutina de ordeño estándar. Capacitar a los trabajadores de la sala en el seguimiento de los procedimientos de ordeño adecuados es fundamental para mantener la máxima calidad de la leche y prevenir las prácticas de ordeño inconsistentes que pueden afectar negativamente la producción y la salud de la ubre.

\section{Manejo de las Vacas y Mastitis}

El manejo ambiental adecuado y la limpieza de las vacas, de la sala de ordeño y del equipo de ordeño son determinantes importantes tanto de la eficiencia del ordeño como del control de las infecciones intramamarias (mastitis).
Las infecciones intramamarias pueden ser causadas por patógenos ambientales o contagiosos. Los patógenos contagiosos se pueden transferir de una vaca a otra durante el ordeño, mientras que los patógenos ambientales pueden infectar a las vacas inmediatamente después del ordeño, mientras el canal del pezón aún está abierto. El uso de guantes, desinfección de pezones antes y después del ordeño, toallas de un solo uso para secar pezones, sistemas de retrolavado y lavado y desinfección adecuados del equipo de ordeño, son procedimientos recomendados para disminuir la propagación de patógenos contagiosos y la aparición de nuevas infecciones intramamarias.

La mastitis ambiental a menudo afecta a rebaños que han controlado las infecciones de mastitis contagiosas. Un medio ambiente limpio es esencial para prevenir la mastitis causada por los patógenos ambientales. Las vacas, los corrales y el material de cama deben mantenerse limpios y secos para minimizar la exposición a patógenos ambientales y reducir el riesgo de desarrollo de mastitis. Además, seguir los procedimientos de ordeño adecuados es un paso importante para reducir la aparición de nuevas infecciones por mastitis ambiental.

1. This document is AN371, one of a series of the Department of Animal Sciences, UF/IFAS Extension. Original publication date October 2021. Visit the EDIS website at https://edis.ifas.ufl.edu for the currently supported version of this publication.

2. Izabella Toledo, regional specialized Extension agent II, dairy, UF/IFAS Extension Northeast District; UF/IFAS Extension, Gainesville, FL 32611.

The Institute of Food and Agricultural Sciences (IFAS) is an Equal Opportunity Institution authorized to provide research, educational information and other services

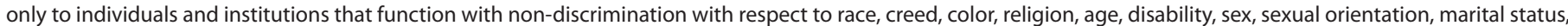

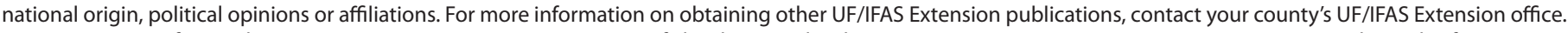
U.S. Department of Agriculture, UF/IFAS Extension Service, University of Florida, IFAS, Florida A \& M University Cooperative Extension Program, and Boards of County Commissioners Cooperating. Nick T. Place, dean for UF/IFAS Extension. 


\section{Manejo de las Vacas y Ambiente de la Sala de Ordeño}

El manejo de las vacas y el entorno del ordeño son determinantes importantes de la eficiencia del ordeño. El proceso de ordeño comienza cuando las vacas se trasladan del establo a la sala de ordeño. Las vacas deben manipularse y llevarse al salón con calma y suavidad. El uso de fuerza física o gritos hará que las vacas se agiten y estresen, lo que creará miedo, y hará que las vacas se muevan rápidamente $\mathrm{y}$ aumente las posibilidades de que las vacas se resbalen y defequen mientras las llevan a la sala de ordeño. Para disminuir aún más el estrés antes del ordeño, también se debe minimizar el tiempo en el corral de ordeño. Cuando las vacas están estresadas, se libera adrenalina en el torrente sanguíneo. La liberación de adrenalina dentro de los 30 minutos posteriores al ordeño interfiere con la liberación de oxitocina e interrumpe la bajada normal de leche. Sin una bajada de leche normal y oportuna, se observa un aumento en el tiempo de ordeño y se puede reducir la cantidad de leche recolectada.

\section{Preparación Previa al Ordeño}

La preparación previa al ordeño consiste en completar los pasos necesarios para preparar la ubre para el ordeño y activar el reflejo de bajada de leche. La leche se almacena principalmente en los alvéolos; el tejido secretor de la ubre y la extracción eficiente de la leche se logra coordinando la bajada de leche con la colocación de la unidad de ordeño. La bajada de leche es una combinación de la liberación de oxitocina y el estímulo del sistema nervioso de la glándula mamaria que proporciona el feedback a los músculos que rodean el tejido secretor de la glándula mamaria para liberar la leche para su posterior recolección.

\section{Procedimientos de Ordeño Paso a}

\section{Paso}

Es importante que todos los operadores responsables del ordeño sigan una rutina constante y sigan todos los pasos de los procedimientos de ordeño recomendados en el orden correcto.

\section{Use guantes}

Los patógenos causadores de la mastitis contagiosa pueden vivir en las manos de los ordeñadores y pueden transmitirse a los pezones de las vacas durante el ordeño. Para ayudar a prevenir la transferencia de patógenos, antes del ordeño, las manos deben lavarse bien con agua y jabón. Además, se deben usar guantes de látex o nitrilo durante el ordeño para minimizar la diseminación de mastitis contagiosa entre las vacas. Durante el proceso de ordeño, las manos deben desinfectarse y los guantes deben limpiarse y cambiarse con regularidad.

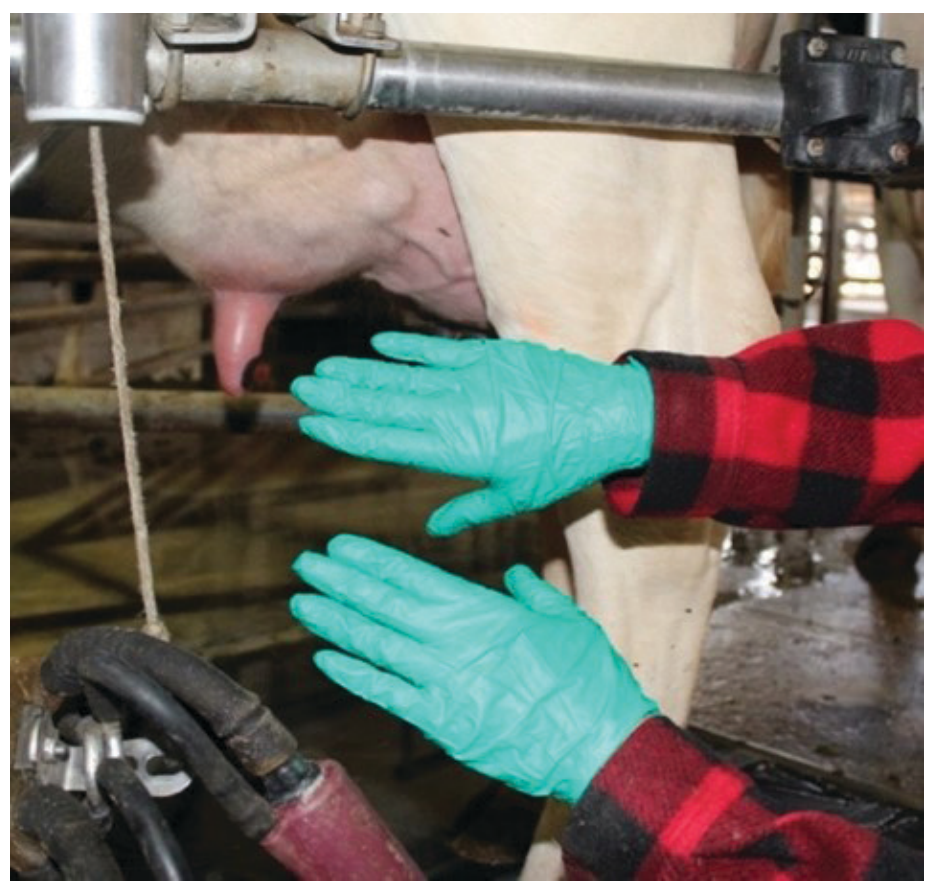

Figure 1.

Credits: Izabella Toledo, UF/IFAS

\section{Pre-sellado}

El pre-sellado se utiliza para eliminar patógenos en las puntas de los pezones antes del ordeño. Los 4 pezones deben summergirse completamente con una solución desinfectante. Para que funcione correctamente, la solución de pre-sellado debe estar en contacto con los pezones por al menos 30 segundos.

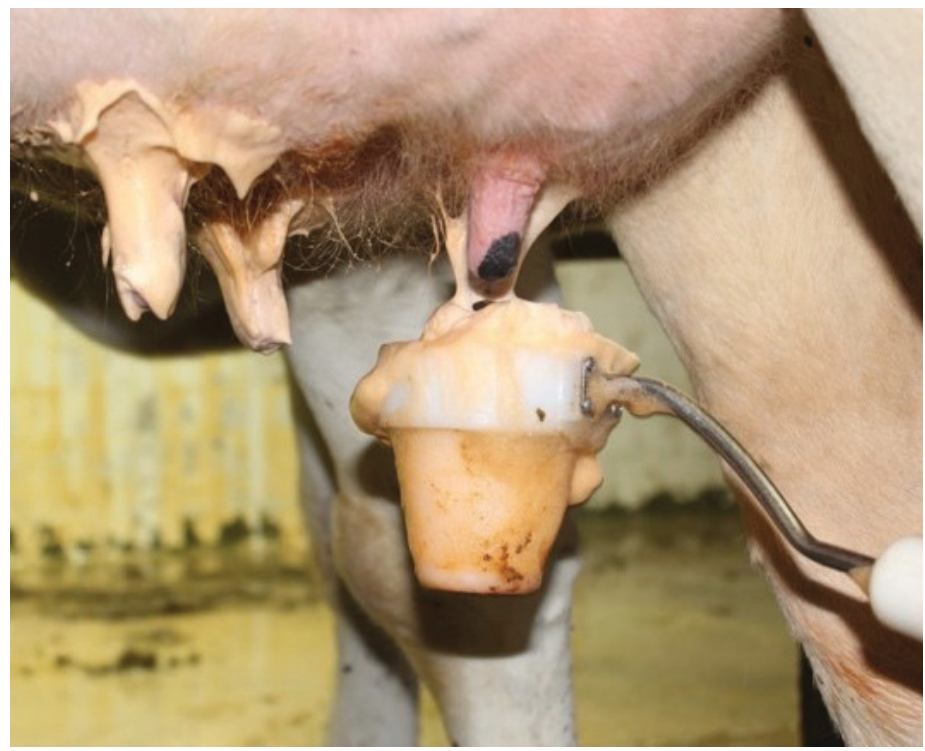

Figure 2.

Credits: Izabella Toledo, UF/IFAS 


\section{Despunte}

El despunte implica en la extracción manual de algunas tiras de leche de cada pezón y se puede lograr antes o después del pre-sellado, sin embargo, debe ocurrir antes de secar los pezones. El método adecuado de extracción es extraer 2-3 chorros de leche por cuarto mamario. Este proceso permite al ordeñador comprobar si hay signos de mastitis y leche anormal, incluidos escamas, coágulos o apariencia acuosa. Además, el despunte ayuda a estimular los pezones y la ubre e inicia el reflejo de bajada de leche. La estimulación eficaz ayuda a aumentar el flujo de leche y reduce el tiempo de funcionamiento de la unidad de ordeño. El despunte debe manejarse usando una taza o tirando leche al piso. La leche no se debe verter en la mano o en una toalla porque esto contribuiría a la propagación de la mastitis entre los pezones y entre las vacas. Para permitir una estimulación adecuada, esta tarea debe tomar alrededor de 10 a 15 segundos por vaca.

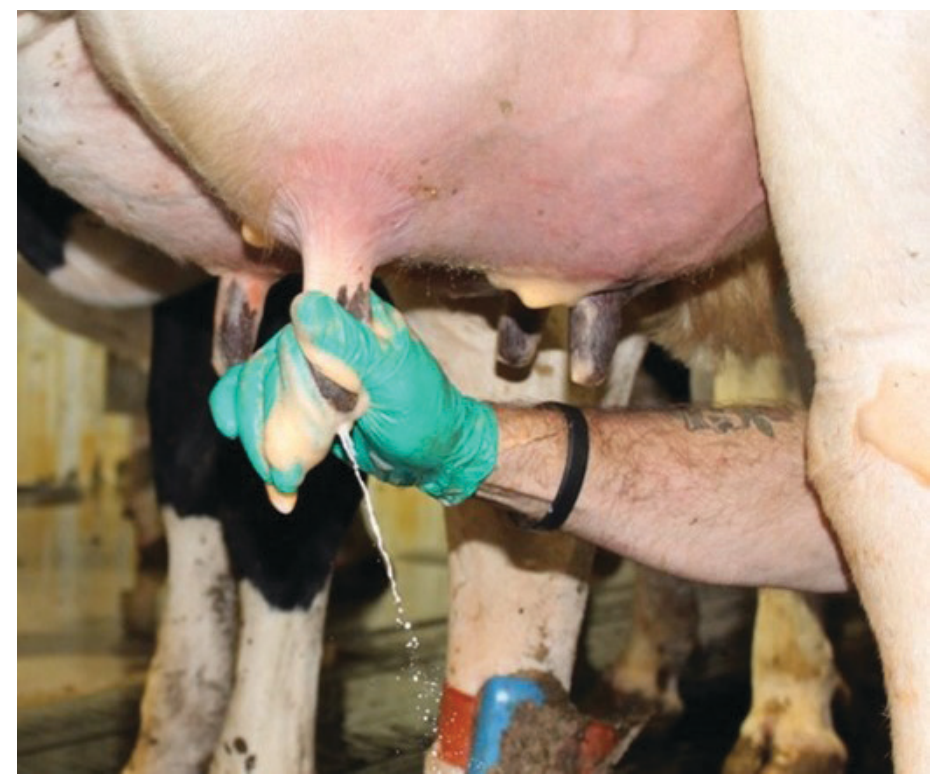

Figure 3.

Credits: Izabella Toledo, UF/IFAS

\section{Secado}

La parte más importante del proceso de desinfección de los pezones es el secado completo de las puntas de los pezones. Se debe usar un solo paño o toalla de papel para limpiar cada pezón con un movimiento giratorio hacia abajo para secar y eliminar cualquier residuo, suciedad y residuo de solución de pre-sellado que pueda estar presente en los pezones. El secado del pezón también evita la posible contaminación de la leche y el pezón por bacterias de la piel presentes en el agua que gotea en la ubre de las vacas. El agua actúa como una vía para que las bacterias entren y contaminen la glándula mamaria. Además, las máquinas de ordeño están diseñadas para permanecer firmemente unidas a un pezón seco. Secar al aire los pezones no es un sustituto eficaz del secado manual con paños individuales o toallas de papel. Es muy importante tener en cuenta que el objetivo final de todo buen programa de control de la mastitis es prevenir la introducción de bacterias en una glándula mamaria sana. En última instancia, los pezones mal secados pueden provocar una mayor incidencia de mastitis.

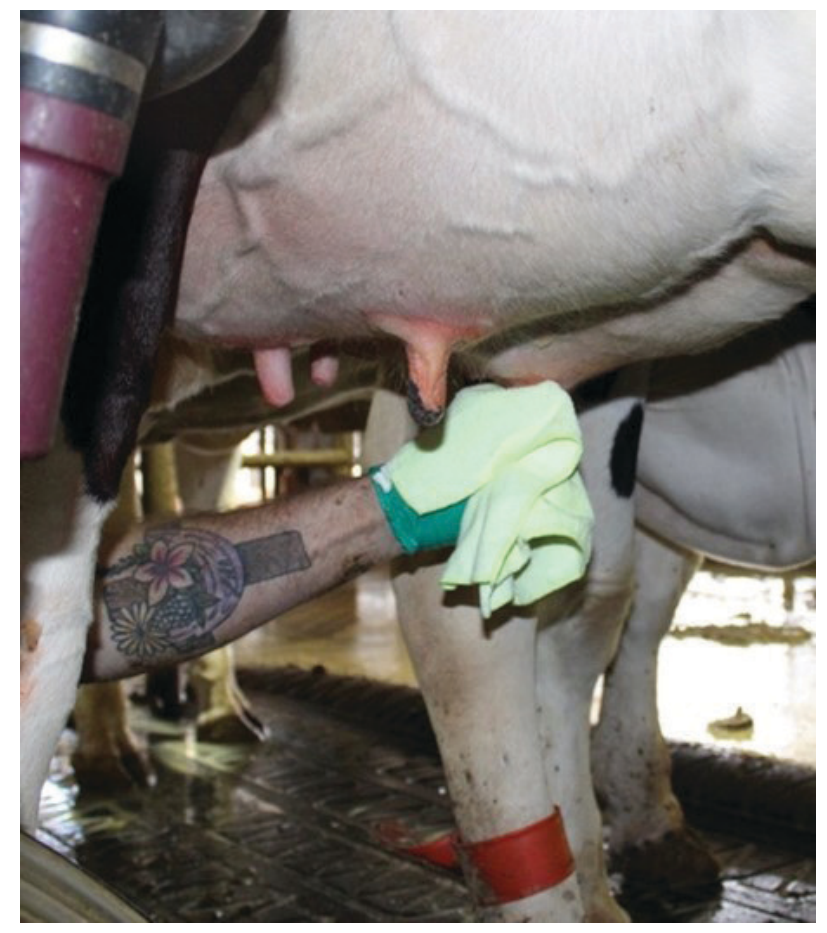

Figure 4.

Credits: Izabella Toledo, UF/IFAS

\section{Colocación de la unidad de ordeño}

El elemento más importante del proceso de colocación de la unidad de ordeño es el tiempo. El tiempo desde el comienzo del proceso de preparación de la vaca hasta que se coloca la unidad se conoce como tiempo de preparación y es fundamental para lograr una óptima bajada de leche. Los niveles de oxitocina en sangre alcanzan su punto máximo alrededor de 60 segundos después de la estimulación inicial de la glándula mamaria. El objetivo es coordinar la bajada de leche con el accesorio de la unidad de ordeño. Por lo tanto, para maximizar la eficiencia del ordeño y el flujo de leche, las unidades deben colocarse dentro de 1 a 2 minutos después de la estimulación del pezón (despunte/secado). Es aceptable un rango de 60 a 120 segundos. Los tiempos de preparación inferiores a 60 segundos o superiores a 3 minutos pueden resultar en un tiempo de ordeño excesivo y/o una producción de leche reducida. Una buena bajada de leche ocurre cuando la leche fluye inmediatamente después de que se coloca la unidad de ordeño. 


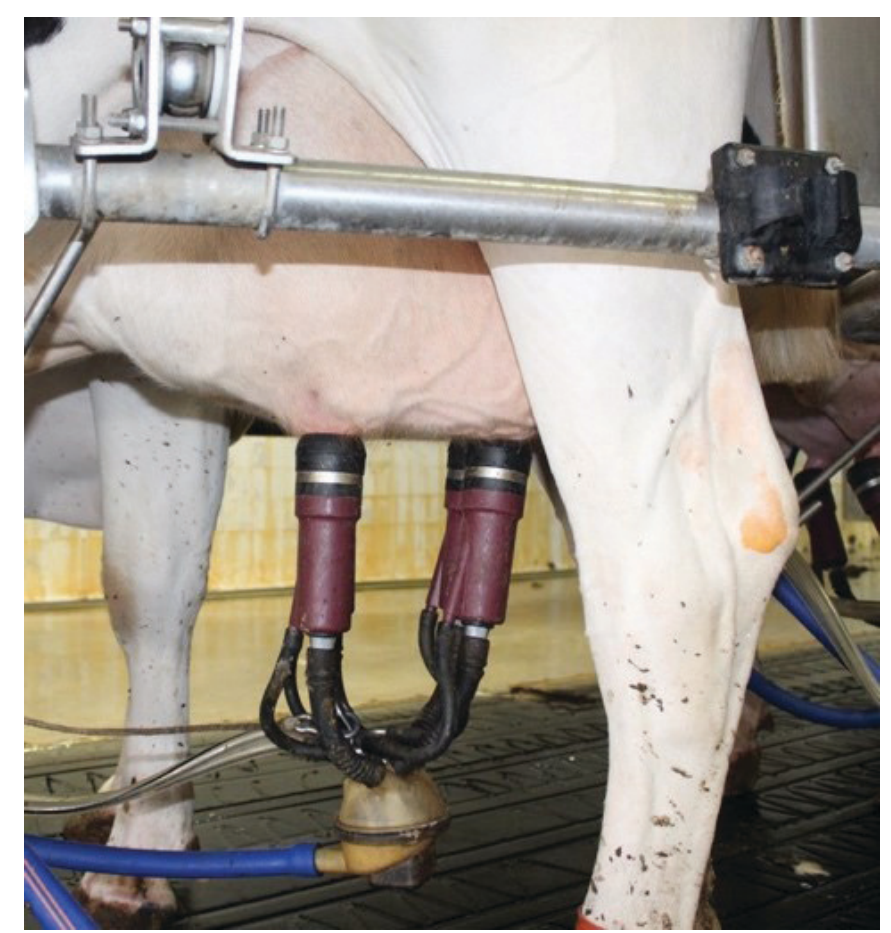

Figure 5 .

Credits: Izabella Toledo, UF/IFAS

La fijación debe realizarse con cuidado para minimizar la entrada de aire en el sistema de ordeño. Ajuste la unidad de ordeño para que cuelgue directamente debajo de la ubre de la vaca y coloque la unidad de ordeño y las mangueras para evitar que se tuerzan. La alineación de la unidad debe ser tal que la salida de la garra apunte entre las piernas de las vacas. La unidad de ordeño debe revisarse y ajustarse para evitar que se deslice durante todo el proceso de ordeño. Cuando la unidad de ordeño no está alineada correctamente, ella puede deslizarse durante el ordeño y quedará demasiada leche en la ubre después del ordeño. El deslizamiento se ha asociado con la contaminación entre cuartos, porque cuando la unidad se desliza, pequeñas gotas de leche pueden ser forzadas hacia el final del pezón. $\mathrm{Si}$ estas gotitas de leche contienen organismos que causan mastitis, ellos pueden ingresar a la ubre y provocar una nueva infección. Asegúrese de volver a colocar las unidades que se caen lo antes posible para que las vacas estén completamente ordeñadas.

\section{Retiro de la unidad de ordeño}

La unidad de ordeño se puede retirar manualmente o con retiradores automáticos. Con cualquiera de los dos procesos, se debe tener cuidado para evitar el exceso de ordeño, que puede aumentar la incidencia de deslizamientos de la unidad y provocar daños en la punta del pezón. Cuando se utilizan retiradores automáticos, la configuración de la unidad debe ajustarse para garantizar que no permanezcan encendidas demasiado tiempo. Por lo general, se recomiendan los retiradores automáticos porque hacen un trabajo constante al retirar la unidad de ordeño. Cuando las unidads se quitan manualmente, asegúrese de cerrar la aspiradora antes de quitarlas. El ordeño completo debe tomar de 4 a 6 minutos por vaca para la mayoría de las vacas. Observe cuidadosamente el flujo de leche o utilice indicadores de flujo de leche para determinar el momento ideal para quitar la unidad de ordeño. Quitar las unidades sin cerrar la aspiradora puede provocar daños en el tejido de la punta del pezón, lo que permite la invasión de bacterias del medio ambiente a la glándula mamaria, y aumenta la incidencia de infecciones intramamarias. Es normal que queden de 2 a 4 tazas de leche en la ubre al finalizar el ordeño. Las vacas debidamente estimuladas y ordeñadas con unidades de ordeño conectadas y que funcionan correctamente no deben tener cantidades excesivamente anormales de leche residual en la ubre.

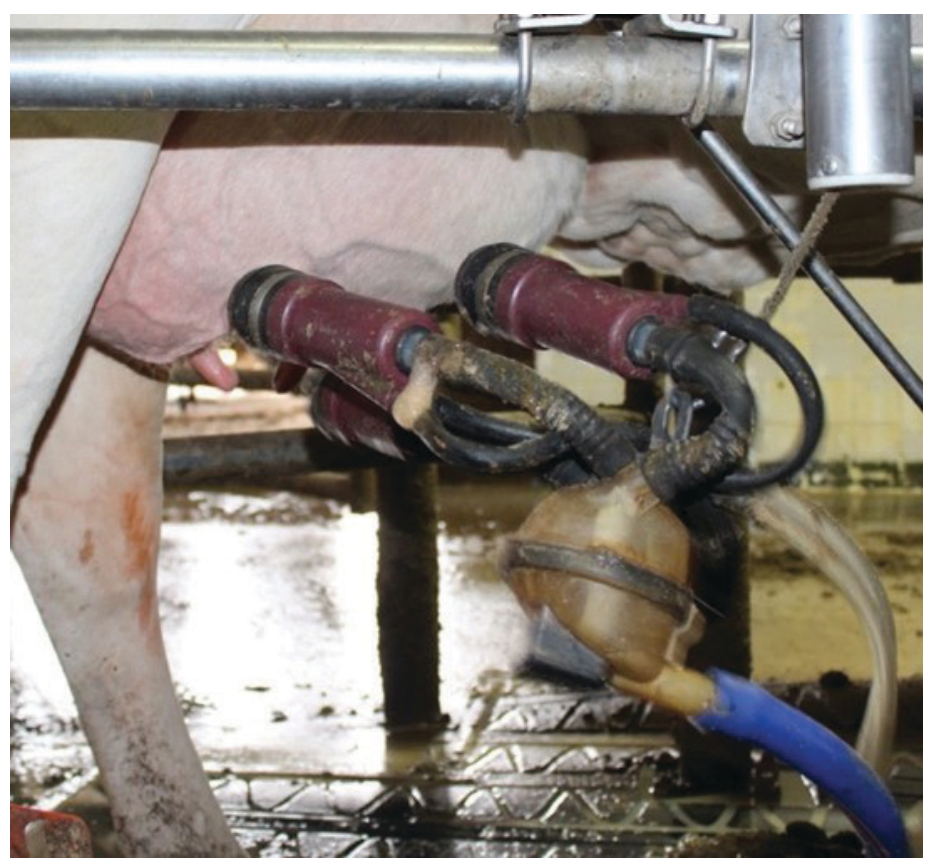

Figure 6.

Credits: Izabella Toledo, UF/IFAS

\section{Post-sellado}

Sumerja por completo cada pezón con la solución de post-sellado inmediatamente después de retirar la unidad de ordeño. Este es un paso importante para controlar la mastitis contagiosa. Un post-sellado eficaz mata el organismo de los pezones y evita que los patógenos entren en el canal del pezón. Para prevenir aún más nuevas infecciones intramamarias, es importante asegurarse de que las vacas permanezcan de pie durante al menos 30 minutos después de que se complete el ordeño. 


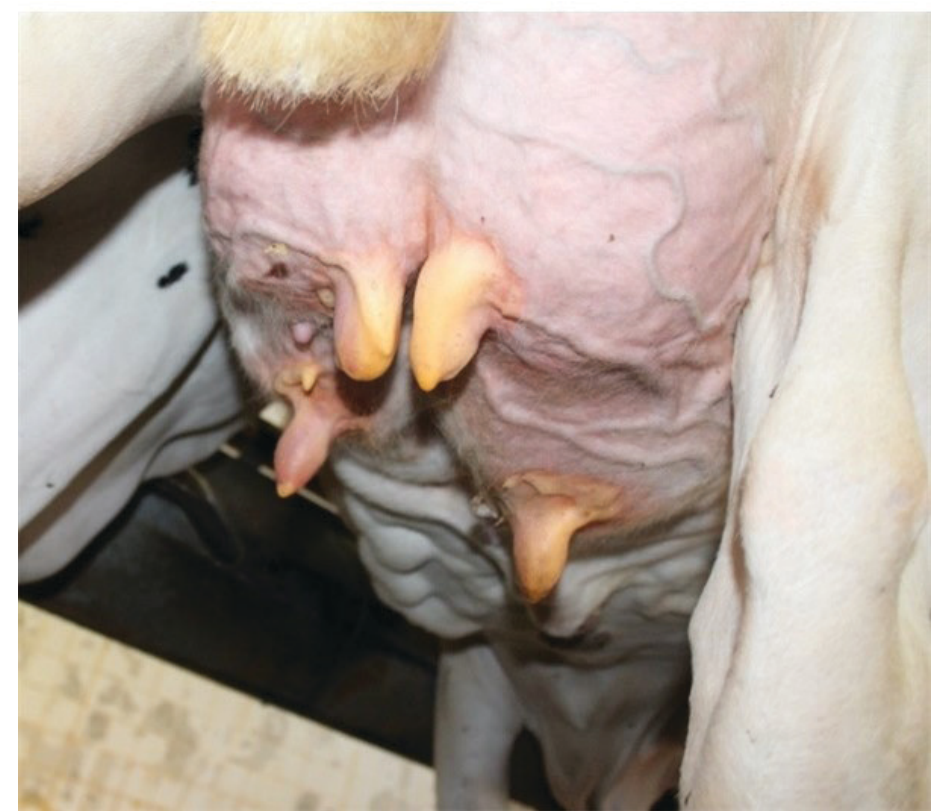

Figure 7.

Credits: Izabella Toledo, UF/IFAS

Línea de Tiempo de la Preparación de la Ubre y Colocación de la Unidad de Ordeño (segundos)

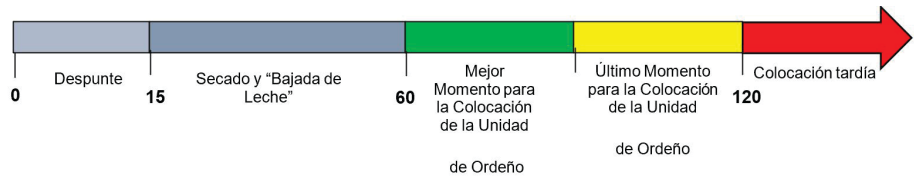

Figure 8.

Credits: Izabella Toledo, UF/IFAS

\section{Ordeñar las Vacas en Orden}

Si no se siguen los procedimientos adecuados, durante el ordeño, una vaca contaminada puede transmitir bacterias a las vacas no contaminadas. Ordeñe primero las vacas sanas, luego las vacas con una salud cuestionable (por ejemplo: compra reciente, o después de un tratamiento), seguido de las vacas con mastitis crónica, alto recuento de células somáticas y/o vacas que muestran signos de mastitis clínica.

\section{La Capacitación del Personal}

Uno de los mayores desafíos para mejorar la eficiencia de la sala de ordeño y controlar y prevenir las mastitis es la motivación, la actitud y el conocimiento de los responsables del ordeño. El primer paso para tener un programa de manejo de ordeño exitoso es establecer y comprender adecuadamente la rutina de ordeño estándar. Los procedimientos operativos estándar deben ser seguidos por todos los ordeñadores y supervisores de sala y deben estar disponibles y visibles en la sala en todo momento. Además, todos los ordeñadores y supervisores de sala de ordeño deben recibir una capacitación rutinaria sobre los procedimientos de ordeño adecuados cada 3-4 meses para mantener frescos los procedimientos en la mente de los ordeñadores en cada ordeño. Los informes de recuentos de células somáticas, casos de mastitis y cultivos bacterianos en tanque a granel también deben informarse y evaluarse con frecuencia. Tomarse el tiempo para asegurarse de que todos los empleados responsables del ordeño estén debidamente capacitados y sigan los procedimientos de ordeño de manera constante, asegurará la producción continua de un producto de alta calidad y con frecuencia puede prevenir prácticas de ordeño inconsistentes que pueden afectar negativamente la producción y la salud de la ubre.

\section{Sumario}

Los objetivos de un buen programa de gestión del ordeño son optimizar la eficiencia del ordeño y la calidad de la leche. El estrés mínimo de las vacas durante el traslado a la sala y durante el ordeño combinado con procedimientos de ordeño consistentes contribuyen a la producción máxima y disminuyen la aparición de infecciones intramamarias. Ordeñe siempre los pezones limpios, secos y bien estimulados y asegúrese de que el equipo de ordeño esté bien desinfectado y funcione correctamente. 


\section{Personal tranquilo y bien capacitado}

Los ordeñadores deben seguir una rutina constante y seguir todos los pasos de los procedimientos de ordeño

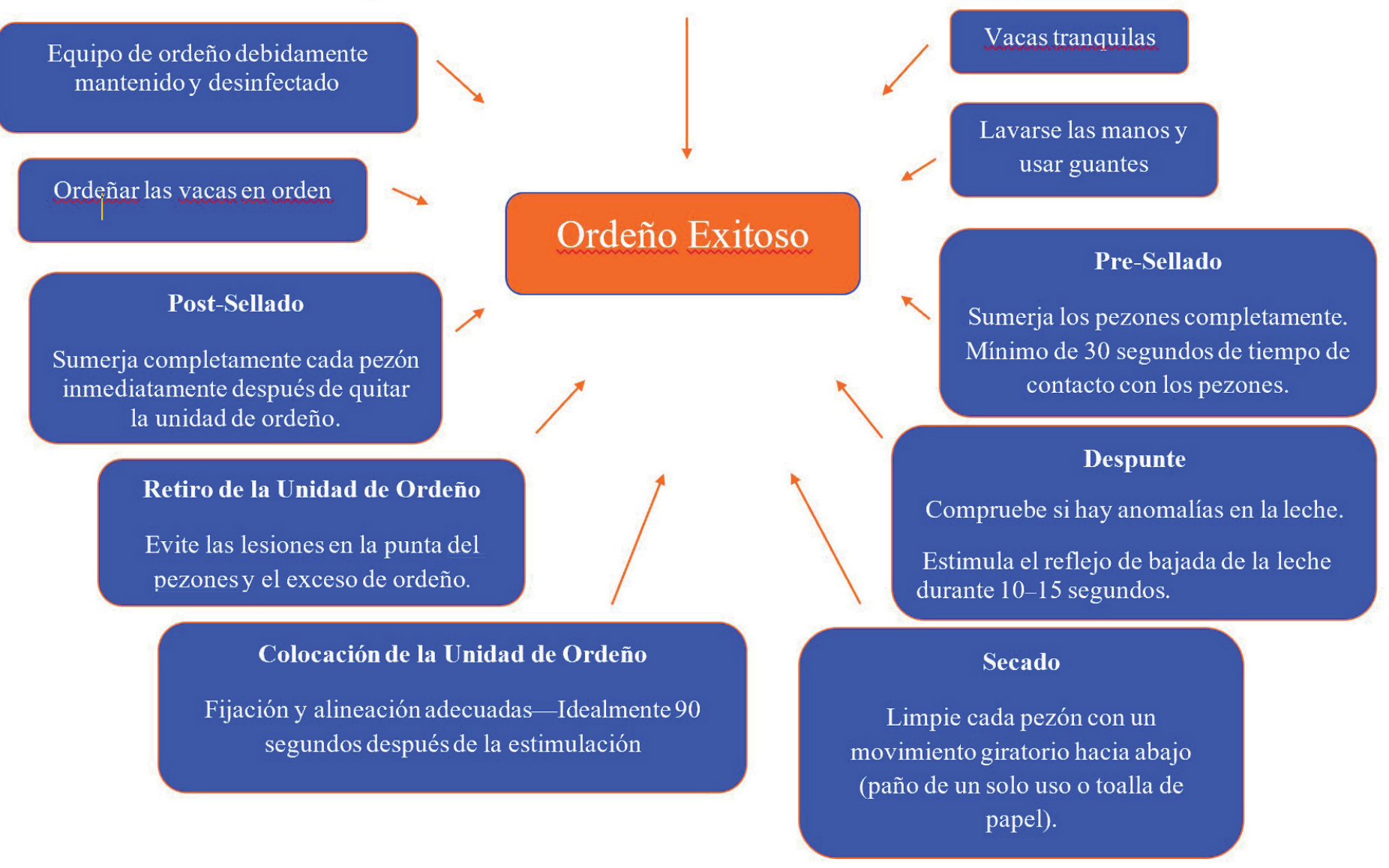

